\title{
Chapter 10 \\ The Competitiveness Issue of the Japanese Economy Under Carbon \\ Pricing: A Computable General \\ Equilibrium Analysis of 2050
}

\section{Shiro Takeda}

\begin{abstract}
Using a computable general equilibrium (CGE) model, this paper investigates the impact of carbon regulations on the Japanese economy. We use an 11sector, 15-region global dynamic CGE model with a time span from 2011 to 2050. We assume that Japan (along with other developed regions) reduces $\mathrm{CO}_{2}$ emissions by $80 \%$ by 2050 and analyze the impact on the Japanese economy. In particular, we consider multiple scenarios of $\mathrm{CO}_{2}$ reduction rates in less developed regions and analyze how changes in $\mathrm{CO}_{2}$ reduction in these regions affect Japan. In addition, we also consider multiple scenarios of the use of a border adjustment policy and analyze its impact. Our simulation results are summarized as follows. First, an $80 \%$ $\mathrm{CO}_{2}$ reduction in Japan generates large negative impacts on the Japanese economy in terms of both the macroeconomy and individual sectors. Second, changes in the reduction rates in less developed regions have only a small impact on Japan. Third, the use of border adjustment in Japan has a small impact on the GDP and welfare of Japan overall but a large impact on output in the energy intensive sectors. When future climate change policies in Japan are discussed, much attention is usually paid to climate policy in less developed regions. However, the second result of our analysis suggests that climate change policy in less developed regions has only a small impact on Japan. In addition, the third result indicates that the effectiveness of border adjustment is limited.
\end{abstract}

Keywords Climate change policy in Japan · Computable general equilibrium analysis $\cdot$ Emissions permit trading $\cdot$ Border adjustment $\cdot$ International competitiveness

\footnotetext{
S. Takeda $(\bowtie)$

Faculty of Economics, Kyoto Sangyo University, Kyoto, Japan

e-mail: shiro.takeda@cc.kyoto-su.ac.jp
} 


\section{Introduction}

The Paris Agreement aims to keep the global temperature increase below $2{ }^{\circ} \mathrm{C}$ (and $1.5^{\circ} \mathrm{C}$ if possible) above the pre-industrial level. However, it has gradually been proven that the level of "Nationally Determined Contributions (NDCs)" provided by countries around the world is not sufficient to meet the Paris Agreement's temperature target. To achieve the Paris Agreement temperature goal, the world needs to aim for more ambitious reduction targets. However, in reality, many countries, including Japan, seem to be reluctant to actively address climate change problems.

The government of Japan aims to reduce $\mathrm{CO}_{2}$ emissions by $80 \%$ by 2050 . However, the government has not yet determined which policy measures to use to achieve the target and does not appear to be actively working on climate change problems. The reason for such an equivocal or passive attitude is the government's concern about negative economic impacts generated by climate mitigation policies. Since Japan has actively promoted energy saving activities, the marginal cost for $\mathrm{CO}_{2}$ reduction is thought to be relatively high. The high marginal abatement cost means that if Japan tries to reduce a large amount of $\mathrm{CO}_{2}$, the country will end up with a heavy economic burden.

In the environmental economics of climate change, computable general equilibrium (CGE) analysis has been widely used to evaluate the economic impacts of climate change policy. For example, the MIT EPPA model (Chen et al. 2015) and OECD ENV-linkages model (Château et al. 2014) are representative examples of CGE models for climate change policy analysis and have been used to analyze various climate change policies around the world. With respect to Japan, there are studies, for example, by Takeda et al. (2012, 2014). These studies have investigated how climate change policy in Japan will affect the macroeconomy and individual economic agents in Japan. In addition, the studies analyzed how policies aiming to lessen the burden on energy-intensive industries will affect the international competitiveness of Japanese industries.

These studies have provided useful insights into Japan's climate change policies. However, there are some shortcomings in the approaches. First, their CGE model was based on a static model, which makes it impossible to depict the dynamic path of the economy with carbon regulations. In reality, many less developed countries are rapidly growing, but at the same time, they are required to reduce their $\mathrm{CO}_{2}$ emissions. A static model is difficult to depict this kind of economic situation.

Second, only a modest $\mathrm{CO}_{2}$ reduction policy was analyzed. Recently, many developed countries have set long-term targets to significantly reduce their $\mathrm{CO}_{2}$ emissions by 2050 (many developed countries have goals of at least $80 \%$ reduction by 2050). However, previous studies assumed reduction rates of less than $30 \%$ for developed countries, which is far lower than the long-term future reduction rates, with no $\mathrm{CO}_{2}$ regulations for less developed countries.

Using a global multiregion dynamic CGE model, this research aims to evaluate the economic impact of the $\mathrm{CO}_{2}$ reduction policy in Japan. To overcome the shortcomings in previous studies, our study has the following features. First, we reflect the 
Table 1 List of sectors

\begin{tabular}{l|l|l|l}
\hline Symbol & Sectors & Symbol & Sectors \\
\hline COL* & Coal & ELE & Electricity \\
\hline CRU* & Crude oil & EIS & Energy-intensive industries \\
\hline GAS* & Gas & OTH & Other industries \\
\hline AFF & Agriculture & SER & Services \\
\hline FOO & Food products & TRS & Transport \\
\hline OIL & Refined oil & & \\
\hline
\end{tabular}

Asterisks indicate fossil fuel sectors (primary energy sectors)

actual long-term reduction target in Japan; in other words, we assume that Japan will reduce $\mathrm{CO}_{2}$ emissions by $80 \%$ by 2050 . We investigate how this reduction policy will affect the Japanese economy in terms of both the macroeconomy (GDP and national income) and individual industries (e.g., outputs of industries).

Second, we analyze how the change in climate policy in other regions, in particular, less developed regions such as China and India, will affect Japan. When climate change policy in Japan is discussed, we often have a strong interest in the climate policy of less developed countries because many people, in particular, business communities, have serious concern that if less developed countries do not take aggressive countermeasures against climate change, $\mathrm{CO}_{2}$ reduction in Japan will damage the competitiveness of Japanese industries and impose a heavy burden on the Japanese economy. To determine whether this argument is indeed the case, this study considers multiple reduction scenarios of less developed countries and then analyzes how changes in reduction rates in less developed countries will affect the Japanese economy. Finally, this study investigates whether border adjustment policies will affect the impacts of $\mathrm{CO}_{2}$ reduction. Although the use of border adjustment can alleviate the burden of $\mathrm{CO}_{2}$ reduction, we analyze how the adoption of border adjustment actually changes Japan's burden.

The rest of the paper is organized as follows. Section 2 describes the CGE model and data used in our analysis, while Sect. 3 defines simulation scenarios. In Sect. 4, we discuss the results of the analysis, and finally, we present our conclusions in Sect. 5.

\section{Model and Data}

We use a simulation approach based on a CGE model. Our model is an extension of the model used in Takeda et al. (2012, 2014, 2019). It is a multiregion model based on the GTAP9 dataset (Aguiar et al. 2016), and we aggregate original regions and sectors in GTAP data into 15 regions and 11 sectors in Tables 1 and $2 .{ }^{1}$ The classification of regions is selected to be consistent with the classification of regions

\footnotetext{
${ }^{1}$ For the aggregation of GTAP data, we used GTAPinGAMS by Lanz and Rutherford (2016).
} 
Table 2 List of regions

\begin{tabular}{|c|c|c|}
\hline Symbol & Region & List of countries included \\
\hline $\mathrm{JPN}^{*}$ & Japan & Japan \\
\hline USA* & United States & United States of America \\
\hline EUR* & European Union & $\begin{array}{l}\text { Austria, Belgium, Cyprus, Czech } \\
\text { Republic, Denmark, Estonia, Finland, } \\
\text { France, Germany, Greece, Hungary, } \\
\text { Ireland, Italy, Latvia, Lithuania, } \\
\text { Luxembourg, Malta, Netherlands, } \\
\text { Poland, Portugal, Slovakia, Slovenia, } \\
\text { Spain, Sweden, United Kingdom, } \\
\text { Bulgaria, Croatia, Romania }\end{array}$ \\
\hline NAM* & North America excl. US & Canada, Mexico, Rest of North America \\
\hline RUS* & Russia & Russian Federation \\
\hline BRA & Brazil & Brazil \\
\hline CSA & Other Central and South American regions & $\begin{array}{l}\text { Argentina, Bolivia, Chile, Colombia, } \\
\text { Ecuador, Paraguay, Peru, Uruguay, } \\
\text { Venezuela, Rest of South America, Costa } \\
\text { Rica, Guatemala, Honduras, Nicaragua, } \\
\text { Panama, El Salvador, Rest of Central } \\
\text { America, Dominican Republic, Jamaica, } \\
\text { Puerto Rico, Trinidad and Tobago, Rest } \\
\text { of the Caribbean }\end{array}$ \\
\hline OEU & Other European regions & $\begin{array}{l}\text { Switzerland, Norway, Rest of EFTA, } \\
\text { Albania, Belarus, Ukraine, Rest of } \\
\text { Eastern Europe, Rest of Europe, Israel, } \\
\text { Turkey }\end{array}$ \\
\hline AFR & Africa & $\begin{array}{l}\text { Egypt, Morocco, Tunisia, Rest of North } \\
\text { Africa, Benin, Burkina Faso, Cameroon, } \\
\text { Cote d Ivoire, Ghana, Guinea, Nigeria, } \\
\text { Senegal, Togo, Rest of Western Africa, } \\
\text { Central Africa, South Central Africa, } \\
\text { Ethiopia, Kenya, Madagascar, Malawi, } \\
\text { Mauritius, Mozambique, Rwanda, } \\
\text { Tanzania, Uganda, Zambia, Zimbabwe, } \\
\text { Rest of Eastern Africa, Botswana, } \\
\text { Namibia, South Africa, Rest of SACU, } \\
\text { Rest of the World }\end{array}$ \\
\hline MDE & Middle East & $\begin{array}{l}\text { Bahrain, Iran, Jordan, Kuwait, Oman, } \\
\text { Qatar, Saudi Arabia, United Arab } \\
\text { Emirates, Rest of Western Asia }\end{array}$ \\
\hline ERS & Eurasia & $\begin{array}{l}\text { Kazakhstan, Kyrgyzstan, Rest of Former } \\
\text { Soviet Union, Armenia, Azerbaijan, } \\
\text { Georgia }\end{array}$ \\
\hline
\end{tabular}


Table 2 (continued)

\begin{tabular}{l|l|l}
\hline Symbol & Region & List of countries included \\
\hline CHN & China & China, Hong Kong \\
\hline IND & India & India \\
\hline SEA & South East Asia & $\begin{array}{l}\text { Brunei Darussalam, Cambodia, } \\
\text { Indonesia, Laos, Malaysia, Philippines, } \\
\text { Singapore, Thailand, Vietnam, Rest of } \\
\text { Southeast Asia }\end{array}$ \\
\hline ASP & Asia Pacific & $\begin{array}{l}\text { Australia, New Zealand, Rest of Oceania, } \\
\text { South Korea, Mongolia, Taiwan, Rest of } \\
\text { East Asia, Bangladesh, Nepal, Pakistan, } \\
\text { Sri Lanka, Rest of South Asia }\end{array}$ \\
\hline
\end{tabular}

Asterisks indicate "developed regions", and other regions are "less developed regions"

in the World Energy Outlook (WEO) 2018 (IEA 2018). In the following, we label five regions, JPN, USA, EUR, NAM and RUS, as "developed regions" and other regions as "less developed regions". 2 The main difference between our model and the model in Takeda et al. $(2012,2014)$ is that (1) the model here is a dynamic one and (2) it considers both electricity generation by renewable energy and carbon capture and storage (CCS) activity. The basic structure of the model is similar to that used in Takeda et al. (2012, 2014). For details, see these papers.

In each region, there are three types of agents: a representative household, government, and firms. We assume perfect competition in all markets, and production is subject to constant-returns-to-scale technology. Since the different sectors have different production structures, we assume different production functions for the sectors. Following the approach in Takeda et al. (2012, 2014), we divide production sectors into two types (fossil fuel and nonfossil fuel sectors) and assume that they have different production functions.

The production of fossil fuel depends heavily on the endowment of natural resources, and fossil fuel plays important roles in our analysis. Thus, we treat fossil fuel sectors differently from other sectors. ${ }^{3}$ Fossil fuel production activities include the extraction of the following three goods: coal (COL), crude oil (CRU), and gas (GAS). Figure 1 depicts the structure of the nested constant elasticity of substitution (CES) production function for fossil fuel sectors. This shows that the production function of fossil fuel sectors is a two-stage CES function. Fossil fuel output is produced as a CES composite of natural resources and nonnatural resource inputs. In turn, the nonnatural resource input is a Leontief composite of capital, labor and other intermediate inputs. E_ES(j) indicates the elasticity of substitution (EOS) between natural resource and nonnatural resource inputs for sector $j$. This specification of

\footnotetext{
${ }^{2}$ Note that some developed regions are included in "less developed regions". For example, Australia is included in "less developed regions" because it belongs to ASP in this classification.

${ }^{3}$ We consider only two types of production functions. However, some studies consider many types of production structures for different sectors. For example, the MIT EPPA model uses several types of production functions (Chen et al. 2015).
} 


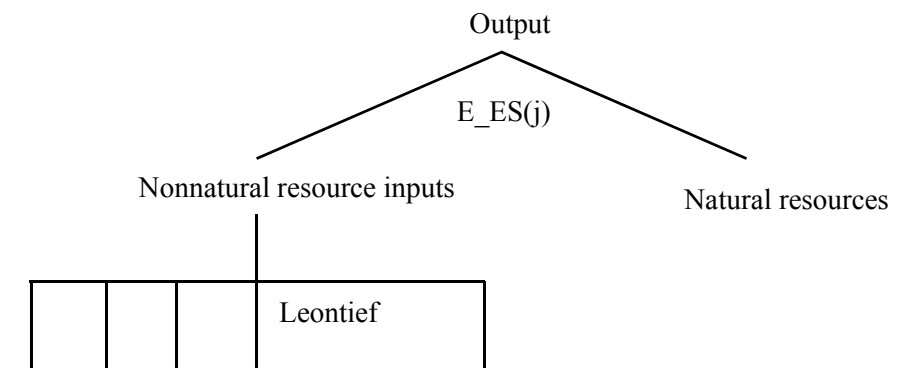

Labor, capital, and intermediate inputs

Fig. 1 Production function of fossil fuel sectors

the production function indicates that natural resources play an important role in the production of fossil fuel. In particular, the values of E_ES(j) greatly affect the change in the output of fossil fuel. The values of E_ES(j) are determined so that the supply elasticity of fossil fuel is equal to the target value.

Nonfossil fuel production (including electricity) has the structure shown in Fig. 2, where numerical values indicate values of the EOS between intermediate inputs and VA(j) indicates the EOS between primary factors in sector $j$. The production of output is from the Leontief aggregation of nonenergy goods and an energy-primary

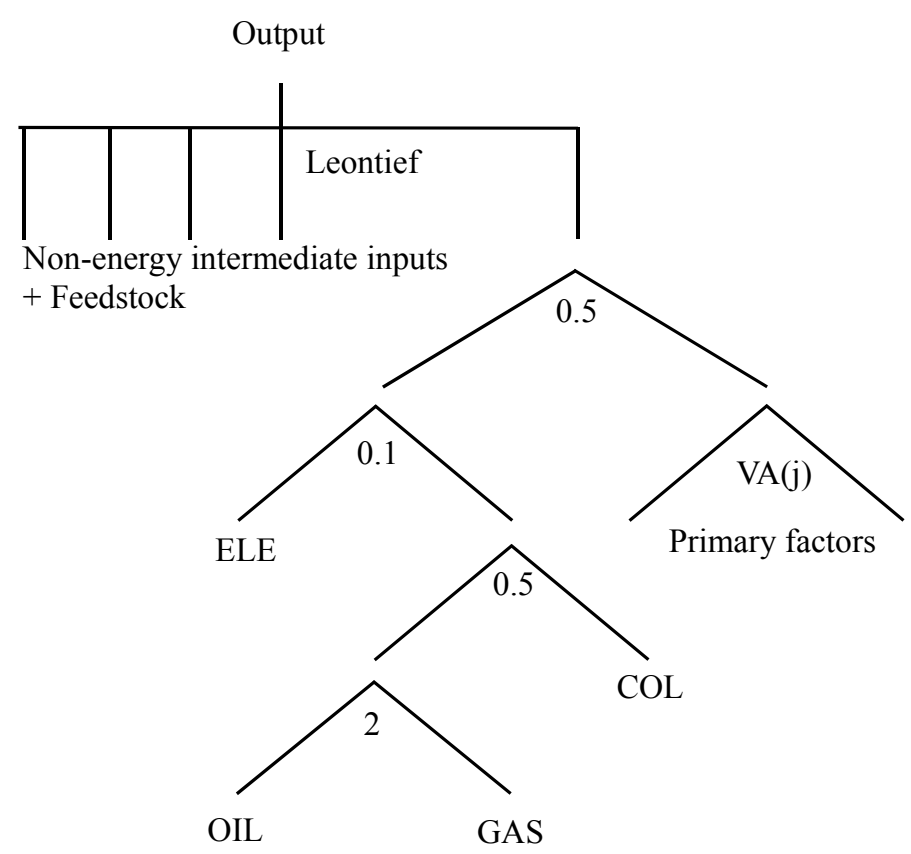

Fig. 2 Production function of nonfuel sectors 


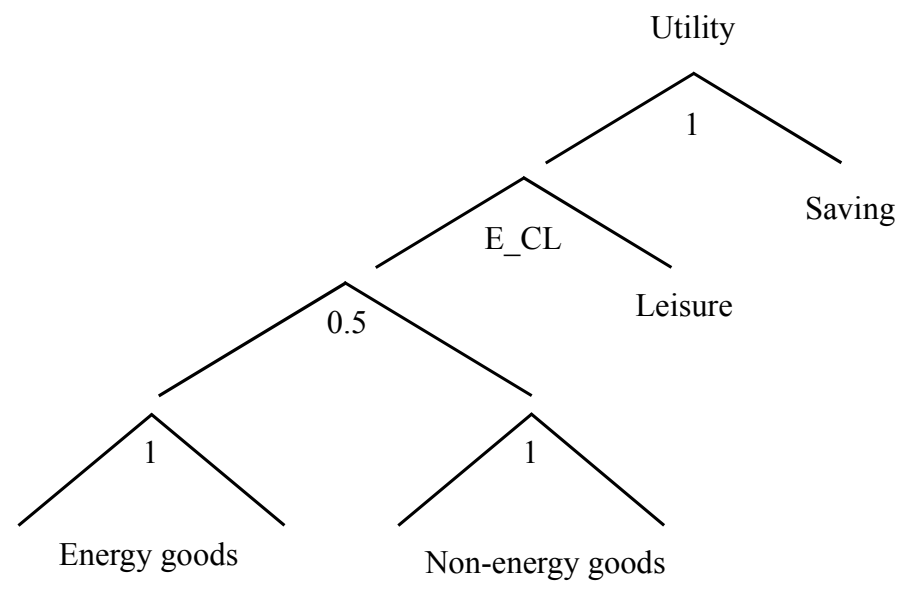

Fig. 3 Utility function

factor composite. The energy-primary factor composite is a nested CES function of energy goods and primary factors. We use this type of nested production structure because we would like to consider the differences in values of the EOS between various inputs.

In addition, with respect to the refined oil sector (OIL), we assume that crude oil enters the production function at the top-level Leontief nest because most crude oil serves as feedstock, which means that it is used as a material. The production functions above include many EOS parameters, and their values are basically taken from Takeda et al. (2012, 2014). ${ }^{4}$

The CES production function means that sector $j$ 's technology in region $r$ is represented by a unit cost function $c_{j r}$. Let $p_{j r}$ denote the price of goods $j$ in region $r$. Then, the zero profit condition (the first-order condition for profit maximization) is given by $c_{j r}-p_{j r}=0$, and it determines the output of sector $j$ in region $r$.

To depict the demand side of the economy, we assume a representative household in each region. The representative household is endowed with primary factors such as capital, labor, land, and natural resources and supplies them to industries. Then, the household allocates its factor income to the purchase of goods and savings (investment). The household's utility has the structure depicted in Fig. 3. We assume that the representative household derives utility from saving, leisure and aggregate consumption. Aggregate consumption is a CES aggregation of a nonenergy composite and an energy composite. The nonenergy composite is a Cobb-Douglas aggregate of nonenergy goods, and the energy composite is a Cobb-Douglas aggregate of energy goods. E_CL indicates the EOS between aggregate consumption and leisure and is determined as follows. First, for the Japan parameter, we use a value of 0.73 , which is estimated by Hatano and Yamada (2007) from leisure and labor data in Japan. To

\footnotetext{
${ }^{4}$ The different CGE studies use different production functions and EOS parameters. Note that these specifications are not necessarily based on empirical evidence.
} 
derive the leisure-consumption elasticity and the leisure time for other regions, we use the same approach as Fischer and Fox (2007).

The household chooses consumption, saving and leisure (labor supply) to maximize its utility subject to the budget constraint. Since we assume a Cobb-Douglas function for the top nest of the utility function, the share of saving in total expenditure (i.e., saving rate) is held constant. The household's income consists of factor income minus tax payments.

Our model is a recursive dynamic model from 2011 to 2050 in which each period includes five years except for the first period (2011-2014), which includes only four years. Investment in each region is financed by saving, and the capital stock owned by the household accumulates over time according to the following formula:

$$
K_{t+\phi}=(1-\delta)^{\phi} K_{t}+\phi I_{t}
$$

where $K_{s}$ is the capital stock in year $s, I_{s}$ is investment in year $s, \delta$ is the annual depreciation rate of capital and $\phi$ is the number of years included in a period (four or five). We assume that the annual depreciation rate is $7 \%$. In addition, we adjust the volume of endowment of primary factors over time. First, the total time used for leisure and labor in each region is adjusted proportionally with the change in its population. Second, the endowment of natural resources used for the production of fossil fuel is adjusted so that the supply of fossil fuel is close to the target value.

Our model is a multiregion global model that depicts international trade in goods and services across regions. To model international trade, we use the Armington assumption (Armington 1969), as many multiregion CGE models do; that is, we assume that goods produced in different regions are imperfect substitutes. Goods from different regions are aggregated through a two-stage CES function: First, imports from different regions are aggregated into composite imports, and then composite imports and domestic goods are aggregated.

Our model covers a long time span (from 2011 to 2050). In the model that aims to analyze climate change policy in the long run, technology improvement and new technology can play an important role. To capture these factors, we consider the following technology improvement and new technology. First, we assume total factor productivity (TFP) growth for every production sector. In addition, we assume autonomous energy efficiency improvement (AEEI) for energy inputs. These technology improvements are assumed to be exogenous. The rate of technology improvement is determined by the method described in Sect. 3.

Second, we assume that electricity is generated not only by conventional energy but also by renewable energy, which does not generate $\mathrm{CO}_{2}$ emissions. Electricity from renewable energy is generated through a production function similar to that of fossil fuel sectors. ${ }^{5}$ We assume that the cost of generating electricity from renewable energy is higher than electricity from conventional energy, and thus, the supply of

\footnotetext{
${ }^{5}$ Electricity generation from renewable energy uses specific resource factors instead of natural resources.
} 
electricity from renewable energy is small in the early period. However, this supply gradually increases as the rise in carbon price increases the price of electricity.

Third, we consider CCS activity. In reality, CCS activity is usually connected with coal-fired electricity generation. However, as with other production sectors, we model CCS activity as an independent activity that provides capture and storage of $\mathrm{CO}_{2}$ by using production factors and intermediate inputs. Since we assume that the cost of providing CCS activity is relatively high, CCS is not supplied at first because it is not profitable. However, the rise in carbon prices from more stringent carbon regulation makes CCS activity profitable, and the amount of CCS increases. We assume that the amount of CCS activity in each region is limited to half of the $\mathrm{CO}_{2}$ emissions in the benchmark year 2011. For example, if $\mathrm{CO}_{2}$ emissions in the benchmark year are $100 \mathrm{MtCO}_{2}$, the upper limit of CCS is given by $50 \mathrm{MtCO}_{2}$. The existence of CCS activity means that net $\mathrm{CO}_{2}$ emissions are equal to gross $\mathrm{CO}_{2}$ emissions minus CCS.

Later, in the simulation, we analyze carbon regulations. We assume that $\mathrm{CO}_{2}$ emissions are regulated by cap-and-trade emissions permit trading. The government in each region imposes a cap on emissions, and emissions permits are traded in each region (no international trade in emissions permits). The market for emissions permits is perfectly competitive, and the permit price is determined so that the permit market is cleared. We assume that permits are initially allocated to industries and the household by auction and that permit auction revenue is rebated to the household in a lump-sum way.

\section{Simulation Scenarios}

In this section, we explain the scenarios for simulation. Table 3 shows the list of scenarios. The BAU scenario is a reference scenario where no (explicit) carbon regulation is executed. To depict the BAU equilibrium, we use the "current policies scenario" in the WEO 2018; that is, we adjust the model so that the BAU equilibrium replicates the situation of "current policies scenarios" in the WEO 2018. To do so,

Table 3 Scenarios

\begin{tabular}{l|l|l}
\hline \multicolumn{2}{l}{ Scenarios } & Explanation \\
\hline \multicolumn{2}{l}{ BAU } & Reference scenarios with no $\mathrm{CO}_{2}$ regulation \\
\hline Reduction rate in LDRs & MRR & Middle reduction rate (40\%) in LDRs \\
\cline { 2 - 3 } & HRR & High reduction rate (60\%) in LDRs \\
\cline { 2 - 3 } & LRR & Low reduction rate (20\%) in LDRs \\
\hline Border adjustment & NBA & No border adjustment \\
\cline { 2 - 3 } & BAA & Border adjustment in all DRs \\
\cline { 2 - 3 } & BAJ & Border adjustment in Japan \\
\hline
\end{tabular}


we adjust the TFP growth rate and the AEEI rate in individual regions so that the paths of GDP and $\mathrm{CO}_{2}$ derived from the model replicate those in the WEO 2018. Although there is no carbon regulation in the BAU equilibrium, improvements in TFP and AEEI restrict increases in $\mathrm{CO}_{2}$ emissions (or reduce $\mathrm{CO}_{2}$ emissions in some developed regions).

In other scenarios, we introduce carbon regulation (cap-and-trade emissions permit trading). In particular, we assume that developed regions (DRs), including Japan, reduce their $\mathrm{CO}_{2}$ emissions by $80 \%$ by 2050 from the 2020 level. ${ }^{6}$ In addition, we consider multiple scenarios in the following aspects: (1) reduction rates in less developed regions (LDRs) and (2) the use of border adjustment policies.

Since we want to analyze how changes in climate change policies in LDRs affect Japan, we consider three different scenarios of reduction rates in LDRs. Scenario MRR is the scenario with a middle reduction rate, where LDRs reduce their $\mathrm{CO}_{2}$ emissions by $40 \%$ (which is half of the reduction rate in DRs). HRR is the scenario with a high reduction rate, where LDRs reduce emissions by $60 \%$. Finally, LRR is the low reduction rate scenario, where LDRs decrease $\mathrm{CO}_{2}$ emissions by $20 \%$.

With respect to border adjustment, we consider the following three scenarios. First, NBA is the scenario with no border adjustment in any region. In this scenario, we analyze the pure effects of carbon regulations. Next, we consider scenario BAA, where border adjustment policies are adopted for EIS sectors in all DRs. Border adjustment in this analysis is a combination of tariffs on the imports of EIS goods and refunds for the exports of EIS goods. ${ }^{7}$ The details of border adjustment are explained in Takeda et al. (2012). Scenario BAJ assumes that only Japan introduces border adjustment. In addition to the BAU scenario, we consider nine scenarios that combine the three reduction rate scenarios with the three BA scenarios.

\section{Simulation Results ${ }^{8}$}

In this section, we explain the results of the simulation. Before examining the impact of carbon regulations, let us investigate the BAU equilibrium. Table 4 reports the level of GDP and $\mathrm{CO}_{2}$ emissions in 2050 in the BAU scenario. Many regions in the world, in particular LDRs in Asia and Africa, continue to grow toward 2050. Although DRs reduce $\mathrm{CO}_{2}$ emissions gradually, $\mathrm{CO}_{2}$ emissions from LDRs increase with their economic growth, and as a result, the world's total $\mathrm{CO}_{2}$ emissions in 2050 reach $45,928 \mathrm{MtCO}_{2}$ in the $\mathrm{BAU}$ scenario.

Table 5 reports GDP and $\mathrm{CO}_{2}$ emissions in Japan in the BAU scenario. In the BAU scenario, while GDP increases, $\mathrm{CO}_{2}$ emissions decrease in Japan. The increase in GDP is mainly due to capital accumulation and improvement in productivity and

\footnotetext{
${ }^{6}$ Note that what is regulated is net $\mathrm{CO}_{2}$ emissions (=gross $\mathrm{CO}_{2}$ minus $\mathrm{CCS}$ ).

${ }^{7}$ The border adjustment in our simulation is the BIEDR type in Takeda et al. (2012).

${ }^{8}$ The simulation is conducted with GAMS. The simulation program and all simulation results are available from the author upon request.
} 
Table 4 GDP and $\mathrm{CO}_{2}$ in 2050

\begin{tabular}{|c|c|c|c|c|}
\hline & \multicolumn{2}{|l|}{ Level } & \multicolumn{2}{|l|}{ Share (\%) } \\
\hline & GDP & $\mathrm{CO}_{2}$ & GDP & $\mathrm{CO}_{2}$ \\
\hline JPN & 8115 & 778 & 3.8 & 1.7 \\
\hline USA & 32,991 & 4,536 & 15.6 & 9.9 \\
\hline EUR & 35,378 & 2,632 & 16.7 & 5.7 \\
\hline NAM & 7437 & 1,352 & 3.5 & 2.9 \\
\hline RUS & 4038 & 2,006 & 1.9 & 4.4 \\
\hline BRA & 7139 & 654 & 3.4 & 1.4 \\
\hline CSA & 6938 & 1,653 & 3.3 & 3.6 \\
\hline OEU & 5706 & 1,265 & 2.7 & 2.8 \\
\hline AFR & 12,294 & 3,048 & 5.8 & 6.6 \\
\hline MDE & 13,053 & 5,032 & 6.2 & 11.0 \\
\hline ERS & 987 & 875 & 0.5 & 1.9 \\
\hline $\mathrm{CHN}$ & 34,505 & 10,297 & 16.3 & 22.4 \\
\hline IND & 14,496 & 5,097 & 6.9 & 11.1 \\
\hline SEA & 12,261 & 3,964 & 5.8 & 8.6 \\
\hline ASP & 15,985 & 2,739 & 7.6 & 6.0 \\
\hline World & 211,324 & 45,928 & 100.0 & 100.0 \\
\hline
\end{tabular}

GDP is in billion US\$, and $\mathrm{CO}_{2}$ is in $\mathrm{MtCO}_{2}$

Table 5 GDP and $\mathrm{CO}_{2}$ emissions in Japan in the BAU scenario

\begin{tabular}{|c|c|c|c|c|}
\hline & \multicolumn{2}{|l|}{ Level } & \multicolumn{2}{|c|}{ Annual growth rate $(\%)$} \\
\hline & GDP & $\mathrm{CO}_{2}$ & GDP & $\mathrm{CO}_{2}$ \\
\hline 2020 & 6,368 & 1,031 & & \\
\hline 2025 & 6,593 & 975 & 0.7 & -1.1 \\
\hline 2030 & 6,827 & 941 & 0.7 & -0.7 \\
\hline 2035 & 7,117 & 920 & 0.8 & -0.5 \\
\hline 2040 & 7,426 & 903 & 0.9 & -0.4 \\
\hline 2045 & 7,736 & 810 & 0.8 & -2.2 \\
\hline 2050 & 8,115 & 778 & 1.0 & -0.8 \\
\hline
\end{tabular}

GDP is in billion US\$, and $\mathrm{CO}_{2}$ is in $\mathrm{MtCO}_{2}$

efficiency (TFP growth and AEEI). On the other hand, the decrease in $\mathrm{CO}_{2}$ is due to AEEI and the increase in renewable energy supply. As explained in the previous section, the paths of GDP and $\mathrm{CO}_{2}$ emissions in BAU are adjusted according to the WEO 2018 scenario.

Figure 4 shows the path of global $\mathrm{CO}_{2}$ emissions in the $\mathrm{BAU}$ and $\mathrm{CO}_{2}$ reduction scenarios. The blue line indicates the path of global $\mathrm{CO}_{2}$ emissions in BAU. Global 


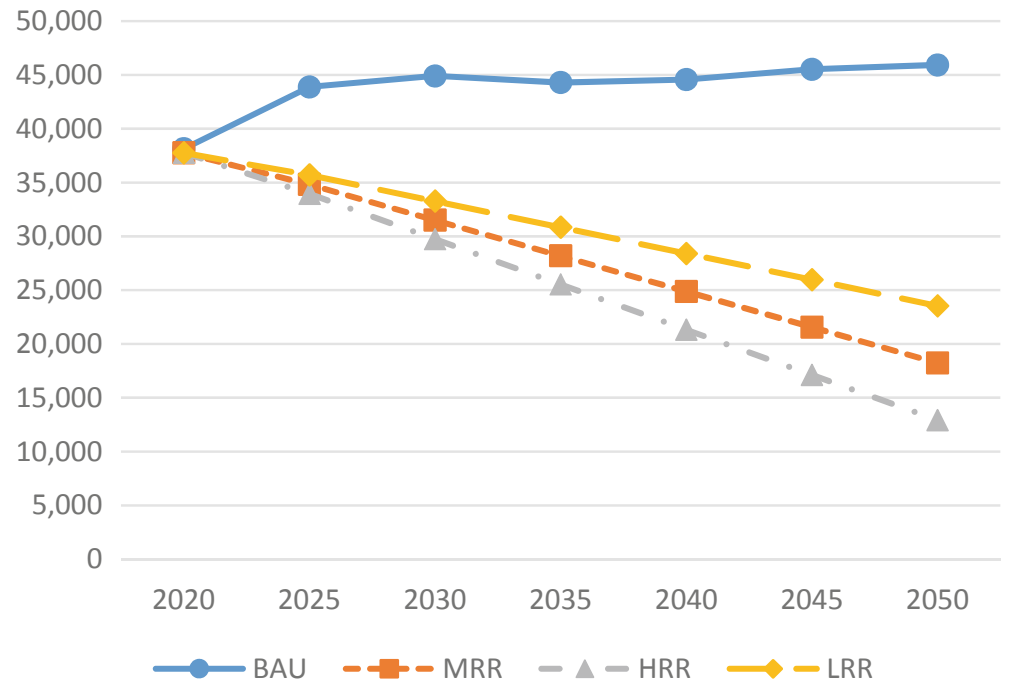

Fig. 4 Global $\mathrm{CO}_{2}$ emissions path $\left(\mathrm{MtCO}_{2}\right)$

$\mathrm{CO}_{2}$ emissions in the BAU scenario will increase in the early 2020s but will then remain almost unchanged, i.e., at approximately $45,000 \mathrm{MtCO}_{2}$. The other three lines indicate the paths of global $\mathrm{CO}_{2}$ in scenarios with $\mathrm{CO}_{2}$ regulations.

Next, let us examine the impact of $\mathrm{CO}_{2}$ regulation on Japan. Table 6 reports the simulation results for 2050. Numerical values in the table represent the percentage change from the BAU equilibrium values in 2050 unless otherwise indicated. First, let us examine the scenarios without border adjustment (the three NBA scenarios). In the simulation with $\mathrm{CO}_{2}$ regulations, Japan reduces $\mathrm{CO}_{2}$ emissions by $80 \%$ by 2050 from the 2020 level, which means that (net) $\mathrm{CO}_{2}$ emissions are reduced to $206.1 \mathrm{MtCO}_{2}$ by 2050. In scenario NBA-MRR, the level of CCS activity reaches approximately 160 $\mathrm{MtCO}_{2}$, and the emissions permit price is approximately US\$850 in 2050. We obtain almost the same values in other NBA scenarios. Because the permit price indicates the marginal abatement cost (MAC) of $\mathrm{CO}_{2}$, this result means that the MAC in Japan is hardly affected by the change in the reduction rates in LDRs.

Next, let us examine macroeconomic variables. In Table 6, we can see the percentage change in consumption, investment, exports, imports, GDP and welfare. ${ }^{9}$ Because of the large reduction in $\mathrm{CO}_{2}$, consumption, exports and imports decrease by approximately $6 \%$ in scenario MRR. As a result, GDP and welfare decrease by approximately $3-4 \%$. The rates of decrease in GDP and welfare are only slightly changed in scenarios HRR and LRR. This means that the impact on GDP and welfare in Japan are not dependent on the rates of decrease in $\mathrm{CO}_{2}$ of LDRs.

Table 6 also reports the impact on output in four sectors: EIS, AFF, OTH and SER. The results show that the output of the EIS sector, which uses energy inputs

\footnotetext{
${ }^{9}$ Welfare here indicates the level of utility of the representative household in each region.
} 


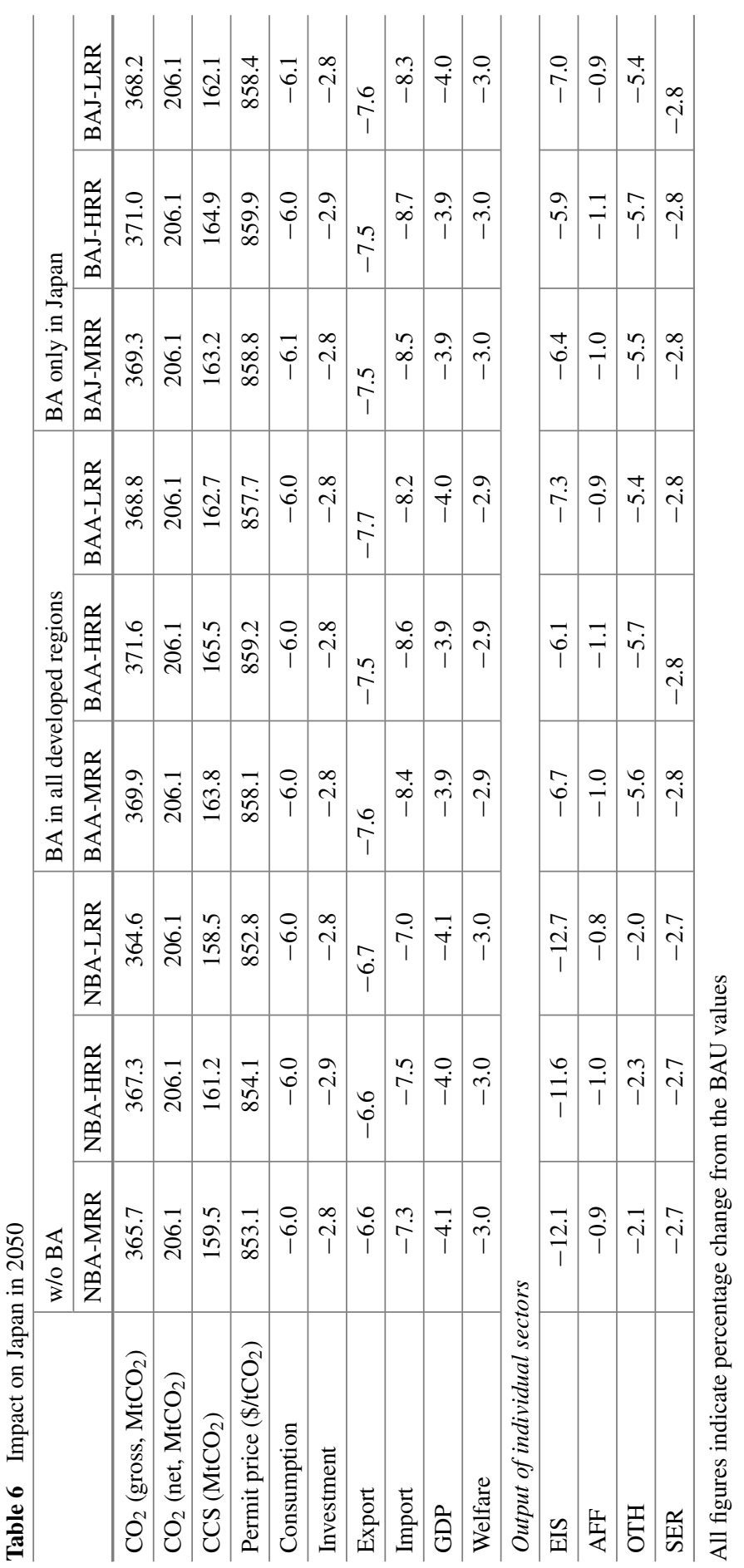


intensively, decreases significantly (by more than 11\%). This means that energyintensive sectors in Japan are likely to experience a large negative impact from an $80 \% \mathrm{CO}_{2}$ reduction. On the other hand, the output of other sectors decreases only slightly. Like the impact on macroeconomic variables, the impact on individual sectors is hardly affected by the change in the reduction rates in LDRs.

We have thus far examined scenarios without border adjustment. Next, let us examine scenarios with border adjustment. BAA is the scenario in which all DRs adopt border adjustment for the EIS sector. Compared to the scenario without border adjustment, the amount of CCS and the permit price increase. However, the changes in CCS and the permit price are not that large, and there is only a small difference with and without border adjustment. With respect to macroeconomic variables, the rates of decrease in GDP and welfare shrink with border adjustment, which means that border adjustment improves the macroeconomic impact. However, the difference with and without border adjustment is also small in terms of macroeconomic variables. As observed above, the impact on CCS, permit price and macroeconomic variables changes only slightly with border adjustment. In contrast, the impact on the outputs of EIS sectors changes to a large extent with border adjustment. To be more precise, the decrease in EIS output is almost halved when border adjustment policies are used.

Finally, let us examine scenario BAJ, where only Japan uses border adjustment. The numerical results for this scenario are almost the same as those in scenario BAA. This means that irrespective of whether other developed regions use border adjustment, Japan is not affected.

Our simulation results show that the Japanese economy is hardly affected by the change in reduction rates in LDRs. In particular, the macroeconomic impact in Japan is almost the same whether the reduction rates in LDRs are high or low. There are two possible reasons for this result. The first reason lies in the industrial structure of Japan. In Japan, more than $70 \%$ of value added is generated in services sectors, and the value added share of energy-intensive sectors is very low. Thus, the change in foreign policies related to carbon restriction and thus energy-intensive sectors has a small impact on Japan. Second, the share of trade (net exports) in GDP is relatively low in Japan (less than 10\%), which also makes it difficult for the change in foreign policies to affect the Japanese economy.

\section{Concluding Remarks}

Using a CGE model, this paper investigates the impact of carbon regulations on Japan. We use an 11-sector, 15-region global CGE model with a time span from 2011 to 2050. We assume that Japan reduces $\mathrm{CO}_{2}$ emissions by $80 \%$ by 2050 and analyze the impact on the Japanese economy. In particular, we consider multiple scenarios of $\mathrm{CO}_{2}$ reduction rates in less developed regions and analyze how changes in $\mathrm{CO}_{2}$ reduction in these regions affect Japan. In addition, we also analyze the impact of border adjustment policies. 
Our simulation results are summarized as follows. First, an $80 \% \mathrm{CO}_{2}$ reduction in Japan generates a large negative impact on the Japanese economy in terms of both the macroeconomy and individual sectors. Second, the change in the reduction rates in less developed regions only has a small impact on Japan. Third, the use of border adjustment in Japan has a small impact on GDP and the welfare of Japan but a large impact on output in the EIS sector.

Finally, let us mention the policy implications of our research. When future climate change policies in Japan are discussed, much attention is usually paid to climate policy in less developed regions such as China and India. This is because climate change policies in less developed regions are thought to have a large impact on Japan. However, the second result of our analysis indicates that climate change policy in less developed regions has only a small impact on Japan. In addition, in the context of climate change policy in Japan, the need for border adjustment is often discussed. The third result of our analysis suggests that border adjustment has a small effect on mitigating negative macroeconomic impacts but a large effect on mitigating the large negative impact on the EIS industry.

\section{References}

Aguiar A, Narayanan B, McDougall R (2016) An overview of the GTAP 9 data base. J Glob Econ Anal 1(1):181-208. https://doi.org/10.21642/jgea.010103af

Armington PS (1969) A theory of demand for products distinguished by place of production. IMF Staff Papers 16

Château J, Dellink R, Lanzi E (2014) An overview of the OECD ENV-linkages model: version 3. OECD environment working papers, No. 65, OECD Publishing, Paris. https://doi.org/10.1787/ $5 j z 2 q c k 2 b 2 v d-e n$

Chen Y-HH, Paltsev S, Reilly JM, Morris JF, Babiker MH (2015) The MIT EPPA6 model: economic growth, energy use, and food consumption. Joint program report series report 278, 43. http://glo balchange.mit.edu/publication/16262

Fischer C, Fox AK (2007) Output-based allocation of emission permits for mitigating tax and trade interactions. Land Econ 83(4):575-599

Hatano T, Yamada M (2007) The household behavior and the effects of public policy: investigation and estimation of structural parameters. In: Tachibanaki $\mathrm{T}$ (ed) The size of government and social security system. Tokyo University Press, Tokyo, pp 203-222 (in Japanese)

IEA (2018) World energy outlook 2018, OECD. International Energy Agency, https://www.oecdilibrary.org/energy/world-energy-outlook-2018_weo-2018-en

Lanz B, Rutherford T (2016) GTAPinGAMS: multiregional and small open economy models. J Glob Econ Anal 1(2):1-77. https://doi.org/10.21642/jgea.010201 af

Takeda S, Tetsuya H, Arimura TH (2012) A computable general equilibrium analysis of border adjustments under the cap-and-trade system: a case study of the Japanese economy. Clim Change Econ 03(01). https://doi.org/10.1142/s2010007812500030

Takeda S, Arimura TH, Tamechika H, Fischer C, Fox Alan K (2014) Output-based allocation of emissions permits for mitigating the leakage and competitiveness issues for the Japanese economy. Environ Econ Policy Stud 16(1):89-110. https://doi.org/10.1007/s10018-013-0072-8

Takeda S, Arimura TH, Sugino M (2019) Labor market distortions and welfare-decreasing international emissions trading. Environ Resource Econ 74(1):271-293. https://doi.org/10.1007/s10 640-018-00317-4 
Shiro Takeda is a professor of Faculty of Economics at Kyoto Sangyo University and a member of the Research Institute for Environment Economics and Management at Waseda University. His research focuses on climate change policies in Japan and computable general equilibrium analysis. He holds his Ph.D. in Economics from Hitotsubashi University. In 2010, he is awarded Young Achievement Award from Society for Environmental Economics and Policy Studies in Japan.

Open Access This chapter is licensed under the terms of the Creative Commons Attribution 4.0 International License (http://creativecommons.org/licenses/by/4.0/), which permits use, sharing, adaptation, distribution and reproduction in any medium or format, as long as you give appropriate credit to the original author(s) and the source, provide a link to the Creative Commons license and indicate if changes were made.

The images or other third party material in this chapter are included in the chapter's Creative Commons license, unless indicated otherwise in a credit line to the material. If material is not included in the chapter's Creative Commons license and your intended use is not permitted by statutory regulation or exceeds the permitted use, you will need to obtain permission directly from the copyright holder. 